\title{
É AINDA UMA CASA PORTUGUESA COM CERTEZA? CASA COMO POTÊNCIA SEMÂNTICA NO ROMANCE PORTUGUÊS DO SÉCULO XXI
}

IS IT STILL A PORTUGUESE HOUSE FOR SURE?

HOUSE AS A SEMANTIC POTENCY IN THE PORTUGUESE NOVEL OF THE 21ST CENTURY

Bruno Mazolini de Barros

Doutor em Teoria da Literatura na Pontifícia Universidade Católica do Rio Grande do Sul PUCRS. 
Resumo: Este artigo busca elencar uma série de romances portugueses, todos publicados a partir do ano 2000, cujo tema da casa é central na narrativa, seja por meio da vivência desse local pelas personagens, seja por reflexões acerca desse lugar presentes no texto. As diversas obras literárias estão perfiladas não só com índices provindos da história da literatura e de estudos sobre a cultura em Portugal, mas também com abordagens do espaço da casa provindas da arquitetura, da sociologia ou da crítica literária. Desse modo, pode-se vislumbrar que, por meio do corpus romanesco aqui destacado, a reiteração desse espaço da narrativa nos textos torna a casa um profícuo dispositivo de leitura da literatura portuguesa do século XXI.

Palavras-chave: cultura portuguesa, romance português do século XXI, casa. 
Abstract: This paper aims to list a series of Portuguese novels, all published since the year 2000, whose theme of the house is central to the narrative, either through the experience of this place by the characters or by reflections about this environment present in the text. The various literary works are outlined not only with indices from the history of literature and studies on culture of Portugal, but also with approaches to home space from architecture, sociology, or literary criticism. In this way, it can be glimpsed that, through the novels here highlighted, the reiteration of this narrative space in the texts makes the house a useful dispositive for reading Portuguese literature of the 21 st century.

Keywords: Portuguese culture, 21st century Portuguese novel, house. 
"Falemos de casas como quem fala da sua alma"

Herberto Helder, "Prefácio", $A$ colher na boca

\section{Fachada}

A pergunta que inspira o título deste trabalho é uma adaptação do famoso verso do fado interpretado por Amália Rodrigues, na década de 1960. Já de antemão, sublinha-se: o presente texto não oferece uma resposta assertiva; o que figuram aqui são algumas constatações que podem gerar diferentes perspectivas, desencadear diversas interpretações.

O percurso da casa como tema e como paradigma de estudo na história da literatura portuguesa é significativo. Ao se eleger o romance como objeto de estudo, pode-se observar que, nos séculos XIX e XX a casa figura como um pujante espaço da narrativa na literatura portuguesa. Com isso em perspectiva, o que pode ser observado no romance português nesse alvorecer do século XXI?

Categorizações acerca da produção literária ou classificações genéricas podem ser redutoras, distorcendo as diversas possibilidades e nuanças que as obras literárias podem manifestar. No entanto, neste contexto, retomar algumas indicações sobre as últimas décadas de produção romanesca portuguesa é importante para se arquitetar este esboço de tendências observadas em narrativas destes últimos anos. 
O romance português deste início de milênio pode ser caracterizado por duas tônicas: a da pluralidade de formas e de temas e a de uma suposta disposição à desvinculação às questões nacionais. A variedade de manifestações e a desassociação temática a Portugal - que inclusive levaria, de certa forma, a uma ruptura maior com o passado, uma matéria importante da literatura portuguesa - são destaque na abordagem de alguns pesquisadores acerca da produção literária do país.

Em "Sociedade e Romance português recente", Miguel Real destaca o cosmopolitismo da literatura portuguesa no século XXI e sua progressiva desvinculação com questões que seriam caracteristicamente atribuídas como portuguesas:

os conteúdos internos (espaço geográfico e social, nacionalidade, identidade e psicologia das personagens, intriga motora da acção) se internacionalizaram do mesmo modo, tornando-se efeitos de um puro cosmopolitismo urbano. Neste sentido, a superior característica nova dos actuais romances portugueses consiste justamente no seu cosmopolitismo, ou dito de outro modo, não são escritos exclusivamente para o público português com fundamento na realidade portuguesa, mas, diferentemente, destinam-se a um público universal e a um leitor único, ecumênico. (REAL, 2011, p. 183-184, grifos do autor)

Nessa amálgama de manifestações, cuja força está em uma "desnacionalização ideológica" (REAL, 2011, p. 184, grifo do autor) do romance português, não 
há, porém, homogeneidade. Segundo o crítico, a pluralidade de estilos, temas e registros dos escritores propicia ao romance português uma multiplicidade descentralizada.

Em O romance português contemporâneo (19502010), Real acrescenta, acerca das personagens da narrativa do século XXI, uma nuança complementar ao indicado anteriormente:

como no final do século XIX, as personagens portuguesas de romances portugueses, ainda que situadas num tempo e num espaço portugueses, perderam, na quase totalidade de romances publicados, o seu vínculo ideológico "portuguesista" (ou nacionalista) [...], para se estatuirem como seres humanos universais, indiferentes aos pormenores locais, trajando, comendo, trabalhando, guerreando e amando como cidadãos do mundo. (REAL, 2012, p. 29, grifos do autor)

Já em Experiência e insignificância, Helena Buescu apresenta dois casos que considera emblemáticos para relacionar a escrita contemporânea portuguesa com a tradição. A pesquisadora destaca especialmente a ausência de homogeneidade entre as diferentes vozes literárias, assim como a impossibilidade de tratá-las como casos geracionais. No entanto, há o que ela designa como "posições de conjunto" dessas manifestações literárias, que relevam uma inclinação maior para o presente do que em relação ao passado. Essa dinâmica da literatura portuguesa contemporânea é tratada como abordagens não contraditórias, e 
sim "solidárias". Além disso, esse passado e presente não estariam em oposição, mas em outro processo, no qual vige a "ideia de que História não é uma cadeia ininterrupta, antes se manifestando e alterando-se, de forma imprevisível (e, aliás, perigosa), no presente" (BUESCU, 2012, p. 19).

Uma preponderância do presente em relação ao passado também é observada em $A$ debilidade do humanismo (A narrativa portuguesa e o século XXI), de Jane Tutikian. No caso da pesquisadora brasileira, a afirmação é de que há um progressivo abrandamento da história e, logo, de conteúdos caros a Portugal, no romance do século XXI. Nesse processo, questões existências que transbordam fronteiras territoriais ganham protagonismo - especialmente os relacionados à fragilidade humana, como a solidão - em detrimento de questões histórico-nacionais. No entanto, a história segue vigente e importante no romance português contemporâneo, e a "literatura continua sendo uma literatura de espaço" (TUTIKIAN, 2017, p. 18, grifo nosso).

Essa diversidade, porém, e mesmo um processo de desvinculação com uma suposta portugalidade, tem raízes em um período anterior ao século XXI. Em "A ficção portuguesa entre a Revolução e o fim de século", Carlos Reis apresenta uma tônica significativa em Portugal, impulsionada pela abertura política e pela descolonização na década de 1970: a pluralidade de motes e formas que se estabelece na literatura 
portuguesa com as diversas manifestações literárias que são normalmente designadas como pós-modernistas (REIS, 2004). ${ }^{1}$ A partir desse último quarto do século XX, o estudioso afirma: "a nossa ficção do final do século XX é inevitavelmente permeável a temas e problemas que ou são específicos da cena portuguesa ou são determinados por movimentos de mais ampla circulação" (REIS, 2004, p. 30-31, grifos nossos).

De volta ao romance do século XXI, a notação acima sobre a espacialidade, feita por Tutikian (2017), remete a uma característica que - juntamente com a multiplicidade de temas e formas e com questões que extrapolam as fronteiras portuguesas, como aponta Reis (2004) - pode ser também reconhecida na literatura pós-Revolução dos Cravos: o espaço da casa figura como lugar significativo no romance português, como destaca Maria Alzira Seixo em Escrever a terra: sobre a inscrição do espaço no romance português contemporâneo. Primeiro, é importante sublinhar o que a estudiosa especifica acerca do título de sua proposta: "Escrever a terra é fazer sentir que entre a história que o romance conta e a personagem que a vive há uma entidade suporte (essa mesma terra) que dá o sentido da pulsação da personagem na história" (SEI-

1 Uma proposta extensa acerca do pós-modernismo em Portugal pode ser encontrada em: ARNAUT, Ana Paula. Post-Modernismo no romance português contemporâneo. Fios de Ariadne - Máscaras de Proteu. Coimbra: Almedina, 2002. Um apanhado conciso sobre o tema é exposto em: SEIXO, Maria Alzira. Postmodernism in Portugal. In: BERTENS, Hans; FOKKEMA, Douwe (Ed.). International Postmodernism: Theory and Literary Practice. Amsterdam: John Benjamins, 1997, p. 405-410. 
X0, 1986, p. 73). Nesse contexto, segundo ela, a casa aparece como um espaço que é motivo fundamental em romances que escrevem a terra; ou seja, que inscrevem a povoação, a localidade, a pátria, o país, enfim, Portugal, em suas narrativas.

No entanto, essa relação entre casa e Portugal é parte da história literária portuguesa e, também, é um tópico relevante em obras bem anteriores ao 25 de Abril. Um apanhado importante sobre essa ligação é a coletânea Escrever a casa portuguesa, organizada por Jorge Fernandes da Silveira. Nessa antologia crítica, diversos lusitanistas discorrem sobre a centralidade da casa em vários textos - seja na narrativa, seja na poesia -, principalmente em produções do século XIX e XX. A proposta do organizador é a de uma "pesquisa que investigue as reflexões em torno da casa portuguesa, entendida agora como uma construção discursiva que pensa o modo português de fixar-se na terra natal. Interesso-me, numa palavra, por "casas de escrita" (SILVEIRA, 1999, p. 14-15, grifo do autor).

Um exemplo que explicita a importância da casa no romance que é publicado até o alvorecer do século XXI é o estudo Entre a casa e a rua: espaço ficcional e a personagem feminina no romance português da segunda metade do século $X X$. Partindo de romances de Agustina Bessa-Luís publicados na década de 1950, passando por José Luís Cardoso, Maria Velho da Costa e chegando a um romance de António Lobo Antunes publicado no ano 2000, Maristela Girola demonstra 
como o espaço da casa - suas tensões e remodelações literárias - é fulcral para configuração e afirmação de um novo feminino no romance português do período (GIROLA, 2013).

Já em Literatura e sociedade: as hipóteses de Abril, João Barrento aponta que, em narrativas portuguesas do final do século passado, a casa e a família seguem como força motriz romanesca, especialmente no que diz respeito ao romance histórico. Em todo caso, a observação do crítico sobre a natureza desse espaço e das relações dos que nele habitam são pertinentes também ao que se persegue nesta leitura, e não somente ao romance histórico. 0 longo trecho a seguir explicita bem uma faceta das relações entre casa, morador e sociedade no romance português:

0 romance não pode tratar a história como uma abstracção. Por isso o romance da tradição burguesa se serve desde sempre de um enquadramento que é a referência privilegiada de história e da História, nomeadamente a casa e a família como suportes de acção e de significação. Este complexo da casa e do clã encontra-se, como sabemos, há muito em crise nas nossas sociedades, e esse é, entre outros, um dos aspectos que levou à proclamação da crise do romance num mundo em que a casa e a família se afundaram, um mundo sem valores nem proibições e tabus a quebrar. Apesar disso (ou talvez por isso mesmo), a casa e o complexo familiar continuam a ser microcosmos importantes no tratamento da História pelo romance. Quase sempre a desagregação das relações familiares, por vezes mesmo a decadência física de uma casa, são espelho de um processo histórico e social que lhes corresponde. (BARRENTO, 2016, p. 38-39, grifo do autor) 
Neste contexto, ainda sobre o século XX, é importante destacar a forte presença de um certo mito da casa portuguesa disseminado no país. Em "Mitificação e paisagem simbólica: o caso do Estado Novo", Joaquim Sampaio explicita a estratégia utilizada pelo salazarismo para a idealização de um Portugal rural, valorizado como um suposto traço autêntico do país. Dentre os processos, ele explica a apropriação do Estado Novo pela ideia de casa portuguesa concebida pelo arquiteto Raul Lino, uma vez que esta estava "associada a um discurso harmonioso, tradicional, nacionalista e atemporal” (SAMPAIO, 2012, p. 111), o que interessava o regime que ocupou mais de 40 anos do poder em Portugal. Em "Cenários do quotidiano doméstico: modos de habitar", Sandra Marques Pereira afirma que a propagação de uma ideia de casa portuguesa promovia, na verdade, um apagamento nas diferenças socioeconômicas habitacionais "por meio de uma unidade nacional ficcionada" (PEREIRA, 2011 , p. 25). Tanto literária quanto politicamente as casas portuguesas desfrutaram de um destaque singular na cena de Portugal, principalmente no século XX.

\section{Dentro de casa}

Algumas particularidades da natureza do espaço da casa, assim como sua vivência por seus habitantes, fazem com que esse local possa exercer um protago- 
nismo em leituras críticas acerca de uma cultura, acerca da literatura portuguesa. Em Identidade, intimidade e domicílio, o arquiteto Juhami Pallasmaa entende a espacialidade em uma casa, sua vivência como lar, como um campo virtual para experiências de diferentes escopos. A casa pode ser um espaço onde diversas vivências do sujeito estão interseccionadas:

O lar não é um simples objeto ou um edifício, mas uma condição complexa e difusa, que integra memórias e imagens, desejos e medos, o passado e o presente. Um lar também é um conjunto de rituais, ritmos pessoais e rotinas do dia a dia. Não pode se construir em um instante, pois possui uma dimensão temporal e uma continuidade, sendo um produto gradual da adaptação da família e do indivíduo ao mundo". (PALLASMAA, 2017, p. 18)

Em Casa e mudança social: uma leitura das transformações da sociedade portuguesa a partir da casa, Sandra Marques Pereira empreende seu estudo tendo como base alguns entendimentos importantes acerca desse espaço. De acordo com a socióloga, como espaço construído, a casa possui uma dimensão cultural e social (além da individual, familiar) e os modos de ocupar, de habitar esse espaço não é só funcional, mas também simbólico e emocional.

Ao afirmar o protagonismo da casa e de seus habitantes em seu estudo, ela destaca a natureza social desses dois, assim como a interface com a sociedade a qual eles pertencem: 
as casas, cuja relevância sociológica decorre do facto de seus "fazedores" serem indivíduos socialmente contextualizados e portanto portadores de determinados quadros valorativos e normativos que, de forma mais ou menos reflectida, acabam por reproduzir espacialmente; os indivíduos, enquanto moradores de casas, também eles socializados, e que nela vivem e que por ela se exprimem, nem sempre com elevada "coerência" e/ou reflexividade, determinadas formas de ser e/ou estar na vida. (PEREIRA, 2016, p. 12, grifos da autora)

Por abarcar essa complexidade, a casa possui um potencial semântico variado. No entanto, a socióloga adverte sobre um risco de interpretação: apesar de indicar muito, a casa não revela tudo de uma sociedade. Além disso, ela alerta para a falácia de uma possível correspondência perfeita, sem matizes do habitar, entre casa e sociedade (PEREIRA, 2016).

Com todas essas potencialidades, a casa habitada, o lar, é um pujante segmento espacial com uma dimensão existencial (ligada principalmente ao sujeito) e outra social (de caráter histórico-cultural). Essas dimensões estão imbricadas, elas contaminam-se. Esse processo pode ser observado não só nos textos literários: ele é, na verdade, característico de relações espaciais. Em Metamorfoses do espaço habitado, Milton Santos destaca pares dialéticos que fazem parte do espaço geográfico, como o novo e o velho, o Estado e o mercado; neste contexto, cabe destacar a dialética do externo e do interno. De acordo com o geógrafo, na realidade do interno de um lugar - de 
uma casa, por exemplo - estariam imbricadas variáveis referentes ao externo, à sociedade, ao país. $\mathrm{Ou}$ seja, o interno acomodaria, em uma escala diferente, questões do externo (SANTOS, 2014).

Em outras palavras, pode-se resumir todas essas potencialidades da casa desta maneira:

entrar na casa é entrar numa outra forma de mundo - ou melhor, numa outra dimensão de mundo, numa outra escala. Miniaturalmente [...], a casa reencena, por muito que possa também ser de outro modo - ou que assim gostemos de o pensar -, o mundo que julgamos deixar lá fora. Com num palco, reencena dentro. E, dentro da casa, o homem não pode deixar de ser actor, por muito que queria ser (e mesmo parcialmente seja) espectador. (BUESCU, 1999, p. 27, grifos da autora)

Esse trecho de "A casa e a encenação do mundo. Os fidalgos da casa mourisca, de Julio Dinis", de Helena Buescu, sintetiza a intersecção de casa e mundo, casa e país, e como isso se aplica inclusive às casas romanescas, objetos de estudo desta presente tese.

Ao se tomar tudo isso em conta, é possível afirmar que o lugar da casa possui um aspecto semântico relevante em diferentes textos narrativos da tradição portuguesa. Em o universo do romance, Roland Bourneuf e Réal Ouellet sublinham: "Longe de ser indiferente, o espaço num romance exprime-se, pois, em formas e reveste sentidos múltiplos até construir por vezes a razão de ser da obra" (BOURNEUF; OUELLET, 1976, p. 131). Nessa concepção, o espaço deixa de ser 
visto como mero cenário e passa a ser, quando não o principal, um elemento essencial na construção de sentido em determinados textos.

Esse conteúdo semântico é ativado por construções específicas da narrativa, e elas podem propiciar, por especificidades de sua própria configuração, maior ou menor relevância a essa categoria narrativa na dinâmica de composição da interpretação de uma obra. 0 que Raquel Trentin Oliveira enfatiza acerca desses processos em Eça de Queirós e o espaço romanesco também é válido para muitos textos narrativos além dos queirosianos, uma vez que esse sentido despertado pela categoria do espaço dependerá, por exemplo:

da caracterização que lhes é dada pela repetição de traços pertinentes; pela acumulação e conjunção de dados; pelas variações qualitativas que sofrem durante o percurso narrativo; pela relação de semelhança ou de diferença que mantêm com os demais elementos da narrativa. (OLIVEIRA, 2014, p. 35)

Em O lugar teórico do espaço ficcional nos estudos literários, Marisa Martins Gama-Khalil, ao retomar diversas abordagens desenvolvidas no século XX acerca dessa categoria da narrativa, destaca um tratamento desenvolvido por Roland Barthes. Segundo a pesquisadora, na concepção de Barthes, a espacialidade não pode ser displicentemente desconsiderada, pois ela pode guardar "potencialidades que podem descorti- 
nar ideologias sendo revistas, desmascaradas, problematizadas" (GAMA-KHALIL, 2010, p. 222).

Com tudo isso em vista, por ser um espaço conjugador de sentidos individuais, sociais e históricos - seja para o indivíduo, seja para a personagem - a casa como espaço narrativo é aqui é tomada como um dispositivo potente, significativo, para se ler o romance português. Segundo Giorgio Agamben, em "O que é um dispositivo?", esse conceito operativo pode se referir a "qualquer coisa que tenha de alguma modo a capacidade de capturar, orientar, determinar, interceptar, modelar, controlar e assegurar os gestos, as condutas, as opiniões e os discursos dos seres viventes" (AGAMBEN, 2005, p. 13). A casa é, como pode ser observado nos romances destacados a seguir, um dispositivo pertinente para se sublinhar alguns matizes na produção ficcional portuguesa destes últimos anos.

\section{Conjunto habitacional}

A casa é um elemento muito prosaico na experiência humana: a vida nesse lugar pode estar presente em qualquer romance. Só nos anos 2000, pode-se observar uma série de narrativas portuguesas cuja relevância desse local está já explicitada em seu título: A casa do diabo, de Mafalda Ivo Cruz (2000); Uma casa na escuridão, de José Luís Peixoto (2002); A casa quieta, de Rodrigo Guedes de Carva- 
lho (2005); A casa do sal, de Cristina Norton (2006); A casa-comboio, Raquel Ochoa (2010); A casa azul, de Cláudia Clemente (2014); Caminho como uma casa em chamas, de António Lobo Antunes (2014); A casa das tias, de Cristina Almeida Serôdio (2017). ${ }^{2}$

A casa, porém, não é espaço com protagonismo somente nessas obras nas quais ela está anunciada em seu título. Sua relevância aparece em outros romances, e a questão do habitar é traço recorrente em obras de autores portugueses de destaque. É um espaço significativo, por exemplo, em Hotel, de Paulo Varela Gomes (2014); em $O$ sonho português, de Paulo Castilho (2015); e em A gorda, de Isabela Figueiredo (2016). Além disso, ao se observar a obra de alguns romancistas relevantes no século XXI, a centralidade da casa aparece de diversos modos em suas narrativas.

Isso pode ser destacado, por exemplo, em conflitos do habitar nos quais personagens de Dulce Maria Cardoso estão envolvidos - conflitos por deter ou não um espaço seu, identitário, uma casa - em seus cinco primeiros romances. Em Campo de sangue (2002), o protagonista inominado, que passa o dia vagando em locais públicos, está privado da vida em um lar, experiência que busca construir com a mulher pela qual está obcecado. Em Os meus sentimentos (2005), a protagonista está em uma disputa simbólica com a fi-

2 As datas indicadas entre parênteses ao longo deste capítulo correspondem às de publicação original dos romances em Portugal. 
lha: cada uma delas têm uma memória, uma vivência diferente da casa familiar onde passaram a infância.

Já em $O$ chão dos pardais (2009), a engrenagem da trama conduz a um assassinato em uma casa familiar; uma das personagens, uma refugiada clandestina que trabalha no local, acredita que possuir uma casa é possuir um "destino". Em $O$ retorno (2012), o protagonista está desterrado de seu lar em Angola com a derrocada ultramarina portuguesa e, em Portugal, precisa recomeçar a vida em um hotel. Em seu romance mais recente, o tema da casa persiste na narrativa de Dulce Maria Cardoso. Além de a protagonista ser uma agente imobiliária, em Eliete - A vida normal (2018), a casa figura como espaço identitário, como lugar de memória e mesmo como análoga à vida da heroína.

Um outro exemplo é a elementaridade do habitar em uma casa familiar - as possibilidades ou as impossibilidades de se viver nesse local - nos romances de Jorge Reis-Sá. Em Todos os dias (2006), o espaço está preenchido por memórias dos integrantes da família e fraturado pela perda de um de seus membros. Já em O dom (2007), a distopia proposta pelo autor tira das personagens a possibilidade de habitar uma casa: todos estão presos em um shopping. Em $A$ definição do amor (2015), o significado sentimental do lugar familiar é posto em xeque: a casa é espaço não só de amor e alegrias da infância, mas também de luto eminente e sofrimento. 
Essas situações destacadas são somente ilustrativas, e não revelam a real complexidade das relações das personagens com esse espaço da narrativa nos textos. De qualquer maneira, a casa não é só importante nesses romances e autores citados. Esse lugar é também significativo em outras tantas narrativas publicadas nestes quase 20 anos de literatura do novo milênio. A seguir, estão elencados grupos romanescos que podem desencadear interpretações posteriores, todas tendo o espaço da casa como dispositivo.

O primeiro grupo, o maior, é o que, junto com os romances já elencados até este ponto formam um caleidoscópio de habitações. Em todos eles, a casa não é só um espaço da narrativa importante; neles encontramos principalmente reflexões sobre a natureza de uma casa, da vivência em um lar, questionamentos sobre sua importância e conflitos diretamente relacionados a esse lugar. São eles: Vista da praia, de José Couto Nogueira (2001); O apocalipse dos trabalhadores, de Valter Hugo Mãe (2008); O arquipélago da insônia, de Antônio Lobo Antunes (2008); O ano sabático, de João Tordo (2013); Debaixo de algum céu, de Nuno Camarneiro (2013); O osso da borboleta, de Rui Cardoso Martins (2014); Os memoráveis, de Lídia Jorge (2014); Índice médio de felicidade, de David Machado (2015); Uma senhora nunca, de Patrícia Müller (2016); Quando as girafas baixam o pescoço, de Sandro William Junqueira (2017). 
Esta lista não pode ser tomada de modo definitivo. Outras obras podem vir a integrá-la; ela está condicionada pelo tempo, pelo espaço, pelo repertório de leitura de seu autor. Por meio deste elenco, pode-se, incialmente, propor arranjos menores para que o tema da casa, do habitar um espaço pessoal ou mesmo nacional, possa ser melhor observado no futuro em outras leituras. Com isso em vista, as narrativas estão encabeçadas por terminologias genéricas que, em um debate aprofundado sobre elas, poderão ser revistas. Afinal, aqui está sendo tratado de o que está na superfície dos textos; não são apresentadas neste texto análises extensas e, também, não são descritas dinâmicas subterrâneas que cada um dos romances possa vir a possuir individual ou coletivamente.

Alguns desses romances, por exemplo, podem ser organizados como casas de luto: local onde a perda é sentida e vivida, onde a ausência é latente, seja a de um ente querido, seja de uma condição social não mais possível. Pode-se observar isso em Todos os dias, A casa quieta, Debaixo de algum céu e em Uma senhora nunca.

Há também as casas-corpos, lares que são uma espécie de extensão físico-psíquicas de seus habitantes. Nessa mesma linha, pode-se ver também casas cuja constituição é reflexo da identidade dos seus moradores. Isso pode ser destacado em $A$ gorda, $O$ arquipélago da insónia, Debaixo de algum céu, Os memoráveis, O apocalipse dos trabalhadores, Uma senhora nunca. 
Há as casas femininas, onde mulheres são protagonistas efetivas, seja da narrativa, seja de suas vidas. É o caso de A gorda, A casa do diabo, Uma senhora nunca, $A$ casa azul, $A$ casa das tias.

Outro segmento é o de casas-cavernas: refúgios radicais onde personagens se auto enclausuram, local onde se escondem do mundo, tomados pela solidão. Isso pode ser observado em Vista da praia, $O$ osso da borboleta, $O$ ano sabático, Todos os dias, Índice médio de felicidade.

Há também as casas-ninhos, lugares que reúnem um clã, uma família. Algumas vezes, aparecem como casa da memória, o lar da infância traumática, perdida ou idealizada. A casa do sal, A casa azul, Uma senhora nunca, A casa das tias, Campo de sangue, Uma casa na escuridão, $O$ arquipélago da insónia.

É preciso destacar as casas-hotéis: casos em que o habitar se dá em um lugar não antropológico, ${ }^{3}$ com dinâmicas diferentes dos pressupostos de uma casa pessoal, como em Campo de sangue, Hotel ou $O$ retorno.

Outro tipo são as casas-colmeias: prédios residenciais. Essas moradias aparecem como organismos habitacionais complexos, algumas vezes autônomas e outras inter-relacionadas com seus habitantes. Isso pode ser destacado em Debaixo de algum céu, Cami-

3 Em não lugares, como define Marc Augé (2012): locais não antropológicos, que, diferentemente de uma casa, são impessoais, de natureza prescritiva, espaços onde a identidade do sujeito não pode manifestar-se desimpedidamente, por exemplo. 
nho como uma casa em chamas, Quando as girafas baixam o pescoço.

Há o caso peculiar de casa-texto: A gorda. Esse lugar central na narrativa de Isabela Figueiredo é tão significativo para a narradora-protagonista que sua importância está refletida na estrutura do texto: a organização capitular do romance se dá por meio dos cômodos do apartamento da família. Não só isso, cada dependência da casa congrega um grupo de memórias, de sentimentos, de experiências que pode ser correlacionado a determinados segmentos espaciais.

Como já destacado, os arranjos poderiam ser outros. Pode-se dizer inclusive que essas casas, no final das contas, são só casas, meros lares. Ela é local central na espacialidade do sujeito; sendo assim, aparece em qualquer romance. Poderiam ser meras casas, que, nas narrativas, não tangem a história ou a cultura portuguesa. Pode-se dizer que luto, família, infância e solidão são todos temas ditos "universais", de uma ideia de mundo cosmopolita.

Porém, alguns desses mesmos romances, em um outro conglomerado, podem ser um contraexemplo para esse tipo abordagem. Eles explicitam casas histórico-nacionais. Elas são lugares onde império ultramarino, regime salazarista, Revolução dos Cravos, transição democrática, mudança econômica ou novas dinâmicas sociais de Portugal estão explicitados. Há, em alguns textos, até moradores, ou mesmo residências, que são diretamente comparados a Portugal. 
Esse arranjo pode ser formado por $A$ casa azul, $O$ arquipélago da insónia, Vista da praia, $O$ osso da borboleta, A casa do diabo, A casa-comboio, Uma senhora nunca, $O$ retorno.

Metafórica ou metonimicamente, guardando os devidos contextos, essas últimas ainda são casas portuguesas. E esse tipo de dado não pode ser simplesmente ignorado ao se afirmar, como o faz Miguel Real, que há um "puro cosmopolitismo urbano" (REAL, 2011, p. 183, grifo do autor). Além de terem suas fundações fortemente ligadas ao local e à história nacional, muitas dessas casas estão em lugares afastados, no interior do país até.

\section{Portas abertas}

É importante, após elencar essas listas genéricas, reiterar aqui a conexão possível entre romance e sociedade, entre literatura e cultura da qual ela se origina. 0 trecho a seguir de "Contexto cultural e novo texto português", de Eduardo Lourenço, é relevante para esse mapeamento da presença da casa como espaço narrativo nesses romances da contemporaneidade:

A relação entre texto e Cultura pertence à ordem da reiteração e da circularidade. Um remete ou supõe a outra e por sua vez esta última não adquire a sua forma manipulável sem a textualidade. Acontece, todavia, que das duas realidades só aquela que designamos por cultura é englobante, sem ser totalizável. Isto significa que texto algum significa senão em função 
dessa referência, ao mesmo tempo densa e imprecisa como uma floresta, que é a referência cultural. (LOURENÇO, 2017, p. 418, grifos do autor)

Lourenço prossegue e explica que uma das funções da crítica envolve, em um processo de abstração, explicitar ligações possíveis entre o texto e a cultura:

A ideia de textualidade recorrente é sugestiva e teoricamente produtiva, mas abstracta. Só o corpo cultural fala nela a linguagem que toda a cultura é já em si mesma sem precisar de ser texto. À multiplicidade de leituras que unem e separam o corpo do texto do fundamento cultural, chamamos nós crítica. Quer dizer, uma leitura plural e aberta capaz de converter em texto luminoso o nexo obscuro e, em última análise, indecifrável, que existe entre todo o texto e a cultura que nele se actualiza. (LOURENÇO, 2017, p. 418-419, grifo do autor)

Frisar essa recorrência, essa insistência do tema e do protagonismo do espaço da casa no romance português é algo incontornável. 0 tema, que povoou tanto a criação literária quanto a história da literatura em séculos anteriores, persiste na ficção neste início de século XXI.

Em “Literatura e cultura (Breve apontamento)", Maria das Graças Moreira de Sá sublinha o seguinte acerca de possíveis indícios da sociedade na literatura portuguesa: "Comparar textos da mesma época e anotar os elementos neles constantes é trabalho tão fundamental quanto saber acolher o que neles surge 
de insólito, de individualizador e de promotor dessa mesma sociedade" (SÁ, 1999, p. 13). Desse modo, há espaço para mais perguntas, não só para a que encabeça esta reflexão: o que pode significar esse destaque da casa nesse início de século em Portugal? Em que medida há ou não, por exemplo, um descolamento de questões específicas portuguesas, ao usá-las como dispositivo de leitura? Que dinâmicas entre o público e o privado a vivência desse espaço indicam? O elas dizem não só sobre o ser, mas também sobre o estar, o habitar nestas primeiras décadas do milênio?

Em "Singularidades de uma literatura ocidental: breve apresentação da literatura portuguesa a estranhos", Maria Alzira Seixo afirma que Portugal manteve diferentes contatos e enriqueceu-se culturalmente de diferentes povos ao longo da história. No entanto, ela afirma:

Cada literatura corresponde, porém, à expressão própria de uma cultura; cada literatura representa uma perspectiva específica, mas diferenciada, do mundo que a envolve, porque, se é certo que assume uma matriz cultural comum, essa matriz apresenta-se no entanto diversificada através das personalidades humanas que a concretizam (os seus escritores e pensadores), e refazem-se constantemente na reelaboração inventiva da insistência temática e da repetição de dos sentimentos e emoções, que a evolução dos tempos e a labilidade psicológica e social não cessam de alterar, para dar origem ao paradigma que os estudos de História Literária designam pela relação "tradição/ inovação". (SEIXO, 2001, p. 78, grifos nossos e grifo da autora, respectivamente) 
Assim sendo, em certa medida, as casas escritas nesses romances são ainda uma casa portuguesa, no mínimo, pela sua origem: nascem na literatura portuguesa e relacionam-se com a cultura de Portugal.

Essas casas recentes coabitam a cultura do país com outras tantas de séculos anteriores. Como os apanhados de Maria Alzira Seixo (1986), de Jorge Fernandes Silveira (1999) e Maristela Girola (2013) explicitam, há também, só a título de exemplo, as casas de narrativas propostas por Júlio Dinis, Eça de Queirós, Fernando Namora, José Régio, Augustina Bessa Luís, Maria Velho da Costa, José Cardoso Pires, Carlos Oliveira, José Saramago, Teolinda Gersão, entre tantos outros autores.

Diversas casas de poesia também poderiam ser citadas: como a "pequena casa portuguesa", brevemente mencionada por Camões no Canto VII, estrofe 14, de Os Lusíadas; como a Pequena casa lusitana, que intitula o livro de poemas de António Sardinha; ou como as casas que se proliferam na obra de Sophia de Mello Breyner Andresen e de Herberto Helder. Um dos ícones da cultura portuguesa do século passado, não se pode deixar de mencionar a casa portuguesa com certeza presente no famoso fado interpretado por Amália Rodrigues.

As casas portuguesas são tantas. Em diversas obras, elas são um dispositivo importante para a interpretação. Como foi destacado neste apanhado, sua reiteração como espaço da narrativa e como tema 
persiste no século XXI. Os rearranjos que esse lugar sofre e as tonalidades que ganha - e que ainda podem ganhar, seja via a criação literária ou via interpretação - são múltiplos. De todo modo, de acordo com a perspectiva adotada no processo interpretativo, todas as obras podem vir a tensionar, cada uma das casas ao seu modo, a relação tradição/inovação com a grande fachada da literatura portuguesa.

Ao mesmo tempo, apesar de guardarem traços da sua cultura de origem, seria impróprio circunscrever todos os índices elencados nesses romances a uma questão exclusivamente portuguesa. Eles podem vir a revelar outros horizontes quando, por exemplo, são observados por uma perspectiva comparatista com outras literaturas ou com discursos diversos acerca da sociedade atual. Em “Observar em português”, Helena Buescu destaca a limitação de se restringir dados de obras artísticas somente a sua cultura de origem:

Há, assim, um valor simbólico (e não apenas político) no entendimento da literatura e da cultura portuguesas como entidades não autocontidas e que não se esgotam em si mesmas, antes pressupondo uma plataforma em que história e incidência geográfica se combinam. (BUESCU, 2013, p. 34-35)

Assim, a reiteração da importância do espaço da casa pode ser lida também como marca de um processo maior, e não somente como um traço cultural português refratado no romance contemporâneo. As 
questões que esse espaço evoca podem extrapolar suas paredes ou as fronteiras de Portugal.

Em todo caso, aqui, deixou-se rastros e não respostas. Apontou-se para tendências de casas inscritas no romance português deste início de milênio. Por hora, utilizando-se de um trecho do conto "A casa do mar", pode-se dizer que, na literatura portuguesa do século XXI, casa "não é margem mas antes convergência, encontro, centro" (ANDRESEN, 2006, p. 81). Quanto às casas que ainda não foram escritas ou mesmo lidas, ficam nesta compilação vestígios de seu porvir. Afinal, elas não surgirão sem causas, nem sem casas anteriores. 


\section{Referências}

AGAMBEN, Giorgio. 0 que é um dispositivo? Tradução de Nilcéia Valdati. Outra travessia: revista de literatura. Ilha de Santa Catarina, n. 5, p. 9-16, 2005. Disponível em: https://periodicos.ufsc.br/index.php/Outra/article/viewFile/12576/11743. Acesso em: 12 jun. 2019.

ANDRESEN, Sophia de Mello Breyner. A casa do mar. In: Histórias da terra e do mar. Porto: Figueirinhas, 2006, p. 67-82.

AUGÉ, Marc. Não lugares: introdução a uma antropologia da supermodernidade. Tradução de Maria Lúcia Pereira. 9a. ed. Campinas, SP: Papirus, 2012.

BARRENTO, João. Literatura e sociedade: as hipóteses de Abril. In: A chama e as cinzas: Um quarto de século de literatura portuguesa (1974-2000). Lisboa: Bertrand Editora, 2016.

BOURNEUF, Roland; OUELLET, Réal. $O$ universo do romance. Tradução de José Carlos Seabra Pereira. Coimbra: Livraria Almedina, 1976.

BUESCU, Helena. A casa e a encenação do mundo. Os fidalgos da casa mourisca, de Júlio Dinis. In: SILVEIRA, Jorge Fernandes da (Org.). Escrever a casa portuguesa. Belo Horizonte: Editora UFMG, 1999, p. 27-37.

BUESCU, Helena. Experiência e insignificância. Signótica, v. 24, n. 1, p. 7-21, jan./jun. 2012. Disponível em: https:// www.revistas.ufg.br/sig/article/view/18535/12263. Acesso em: 12 jun. 2019.

BUESCU, Helena. Observar em português. In: Experiência do incomum e boa vizinhança. Literatura Comparada e Literatura Mundo. Porto: Porto Editora, 2013, p. 34-52.

GAMA-KHALIL, Marisa Martins. O lugar teórico do espaço ficcional nos estudos literários. Revista da Anpoll, v. 1, n. 28, p. 213-236, 2010. Disponível em: https://revistadaanpoll. emnuvens.com.br/revista/article/view/166/179. Acesso em: 12 jun. 2019. 
GIROLA, Maristela Kirst de Lima. Entre a casa e a rua: o espaço ficcional e a personagem feminina no romance português da segunda metade do século XX. Curitiba: Juruá, 2013.

HELDER, Herberto. Poemas completos. 2a. ed. Rio de Janeiro: Tinta-da-china Brasil, 2017.

LOURENÇO, Eduardo. Situação da literatura portuguesa. In: O canto do signo. Lisboa: Gradiva, 2017, p. 400-417.

OLIVEIRA, Raquel Trentin. Eça de Queirós e o espaço romanesco. Porto Alegre: EDIPUCRS, 2014.

PALLASMAA, Juhani. Identidade, intimidade e domicílio: observações sobre a fenomenologia do lar. In: Habitar. Tradução de Alexandre Salvaterra. São Paulo: Gustavo Gili, 2017, p. 11-40.

PEREIRA, Sandra Marques. Cenários do quotidiano doméstico: modos de habitar. In:MATTOSO, José (Dir.). História da Vida Privada em Portugal: Os Nossos dias. Lisboa: Temas e Debates / Círculo de Leitores, 2011, p. 16-47.

PEREIRA, Sandra Marques. Casa e mudança social: uma leitura das transformações da sociedade portuguesa a partir da casa. 2 ${ }^{a}$. ed. Casal de Cambra, Portugal: Caleidoscópio, 2016.

REAL, Miguel. Sociedade e romance português recente. In: Arte \& sociedade: Actas das Conferências As Artes Visuais e as outras Artes. Lisboa: Faculdade de Belas Artes da Universidade de Lisboa, 2011, p. 174-189.

REAL, Miguel. O romance português contemporâneo (19502010). Caminho: Lisboa, 2012.

REIS, Carlos. A ficção portuguesa entre a Revolução e o fim de século. Scripta, Belo Horizonte, v. 8, n. 15, p. 15-45, 2.0 sem. 2004. Disponível em: http://periodicos.pucminas.br/ index.php/scripta/article/view/12566. Acesso em: 12 jun. 2019.

SÁ, Maria das Graças Moreira de. Literatura e cultura (Breve apontamento). In: Entre a Europa e o Atlântico. Estudos de literatura e cultura portuguesas. Col. Temas Portugue- 
ses. Imprensa Nacional/Casa da Moeda: Lisboa, 1999, p. 11-15.

SAMPAIO, Joaquim. Mitificação e paisagem simbólica: o caso do Estado Novo. Cadernos do curso de doutoramento em geografia, Porto, vol. 4, 2012, p. 101-122. Disponível em: https://ler.letras.up.pt/uploads/ficheiros/9965.pdf. Acesso em: 12 jun. 2019.

SANTOS, Milton. Metamorfoses do espaço habitado: fundamentos teóricos e metodológicos da geografia. 6a. ed. São Paulo: Editora da Universidade de São Paulo, 2014.

SEIXO, Maria Alzira. Escrever a terra: sobre a inscrição do espaço no romance português contemporâneo. In: A palavra do romance. Ensaios de genologia e análise. Livros Horizonte: Lisboa, 1986.

SEIXO, Maria Alzira. Singularidades de uma literatura ocidental. Breve apresentação da literatura portuguesa aos estranhos. In: Outros erros. Ensaios de literatura. Porto: Ed. Asas, 2001, p. 77-92.

SILVEIRA, Jorge Fernandes da. "Casas de escrita". In: SILVEIRA, Jorge Fernandes da (Org.). Escrever a casa portuguesa. Belo Horizonte: Editora UFMG, 1999, p. 13-21.

TUTIKIAN, Jane. A debilidade do humanismo (A narrativa portuguesa e o século XXI). Literatura em debate, v. 11, n. 20, p. 8-20, jan./jun. 2017. Disponível em: http:// revistas.fw.uri.br/index.php/literaturaemdebate/article/ view/2659. Acesso em: 12 jun.2019. 